\title{
Retraction Note: A flood disaster relief emergency material distribution strategy based on people's psychological perception
}

\author{
Yinzhen Zhong ${ }^{1}$
}

Published online: 6 December 2021

C) Saudi Society for Geosciences 2021

Retraction Note: Arabian Journal of Geosciences (2021) 14: 851 https://doi.org/10.1007/s12517-021-07179-z

The Editor-in-Chief and the Publisher have retracted this article because the content of this article is nonsensical. The peer review process was not carried out in accordance with the Publisher's peer review policy. The author has not responded to correspondence regarding this retraction.

The original article can be found online at https://doi.org/10.1007/ s12517-021-07179-z.

Yinzhen Zhong

jiangwuxue_dg@163.com

1 Department of Economics\& Finance, Dongguan

Polytechnic, Dongguan 523808, China 